\title{
A case study about acquisition of mechanically fixed cutting inserts
}

\author{
Raluca Daicu ${ }^{1, *}$, Valentin Diţu, and Gheorghe Oancea ${ }^{1}$ \\ ${ }^{1}$ Transilvania University of Braşov, Department of Manufacturing Engineering, Mihai Viteazu No. 5, \\ Braşov, Romania
}

\begin{abstract}
During the process of turning metals there are used cutting inserts that can be acquisitioned from different producers. Because the offer is varied the acquisition must be made after an economical analysis that includes experimental tries. The paper presents an acquisition methodology for metallic carbide cutting inserts and presents a case study. This research was developed using three batches of cutting inserts acquisitioned from different producers. The specimen material was 1C45 and using the electrical current at cutting, the batches were analysed from qualitative and economical point of view.
\end{abstract}

\section{Introduction}

During metal cutting process with good electricity conductor edges it appears an electrical current due mainly to the difference of temperature between the cutting zone and the cold elements of the part-tool thermocouple. Previous research [1-8] showed that it exists a direct dependency between the voltage of the electrical current at cutting and the temperature in the cutting zone: the higher the temperature is, the higher the voltage of the electrical current is.

The authors demonstrated, in a previous research [9], at drilling process, a connection between the electrical current at cutting and the quality of the cutting edges, by microscopically examination of the drills edges and identifying causes of the high electrical current voltage, and led to the conclusion that the electrical current is sensible to any imperfection of the drill edge. Based on this research, the authors developed, in research [10], a methodology for drills acquisition, where two drill batches from two different suppliers were compared from qualitative and economical point of view.

Regarding turning process, the previous research [11] uses the influence of cutting speed on the electrical current at cutting to highlight quality differences between cutting inserts produced in different countries, and research [12] shows that the voltage value of the electrical current at cutting can be used for quality appreciation of the metallic carbide cutting inserts.

Based on the presented facts, in this paper is used the electrical current at cutting to develop an acquisition methodology for metallic carbide cutting inserts and presents a case study, comparing three batches of cutting inserts.

${ }^{*}$ Corresponding author: raluca.daicu@unitbv.ro 


\section{Analysis of the quality of metallic carbide cutting inserts coated with titanium}

There were acquisitioned three batches of metallic carbide cutting inserts, from three different producers, at different prices, each batch having 10 inserts. The producers are named A, B and C. The type of the metallic carbide cutting inserts is WNMG080408 and it was used a MWLNR $2020 \mathrm{~K} 08 \mathrm{~N}$ type support. The acquisitioned cutting inserts are similar from the material point of view (type $\mathrm{P}$ for steel), coated with titanium, and with a similar shape of the rake surface.

The experimental stand is presented in Figure 1 and its elements are: an universal lathe (1), part (2), cutting tool (3), electrical current collector (4), a digital multi-meter with a data acquisition function (5) and a PC (6). The multi-meter has a software that allows data acquisition from second to second and exports the measured values in an Excel file (Figure 2).
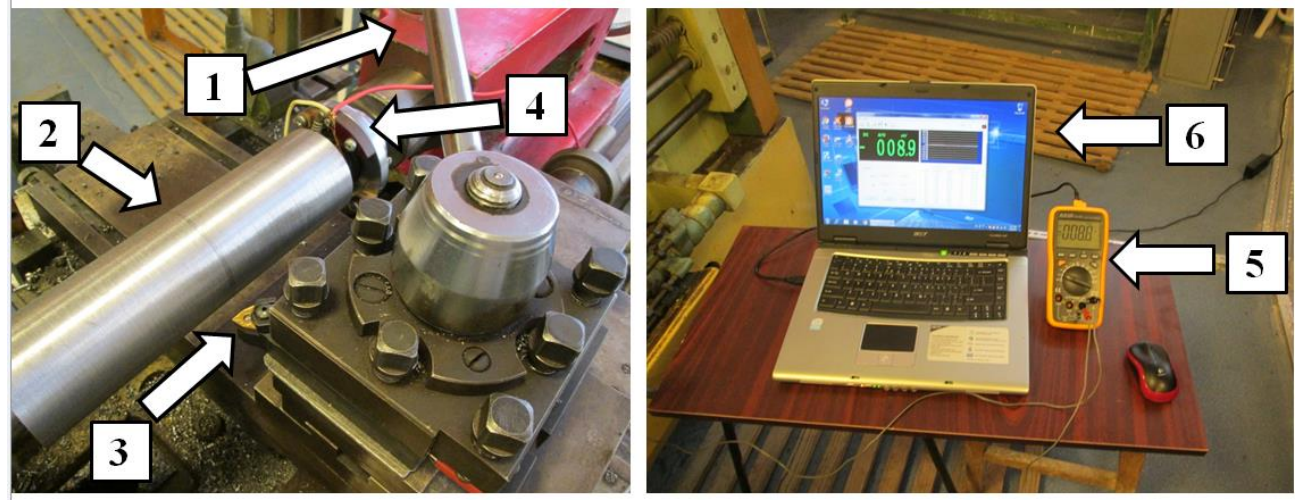

Fig. 1. Experimental stand used in measuring process of the electrical current at turning.

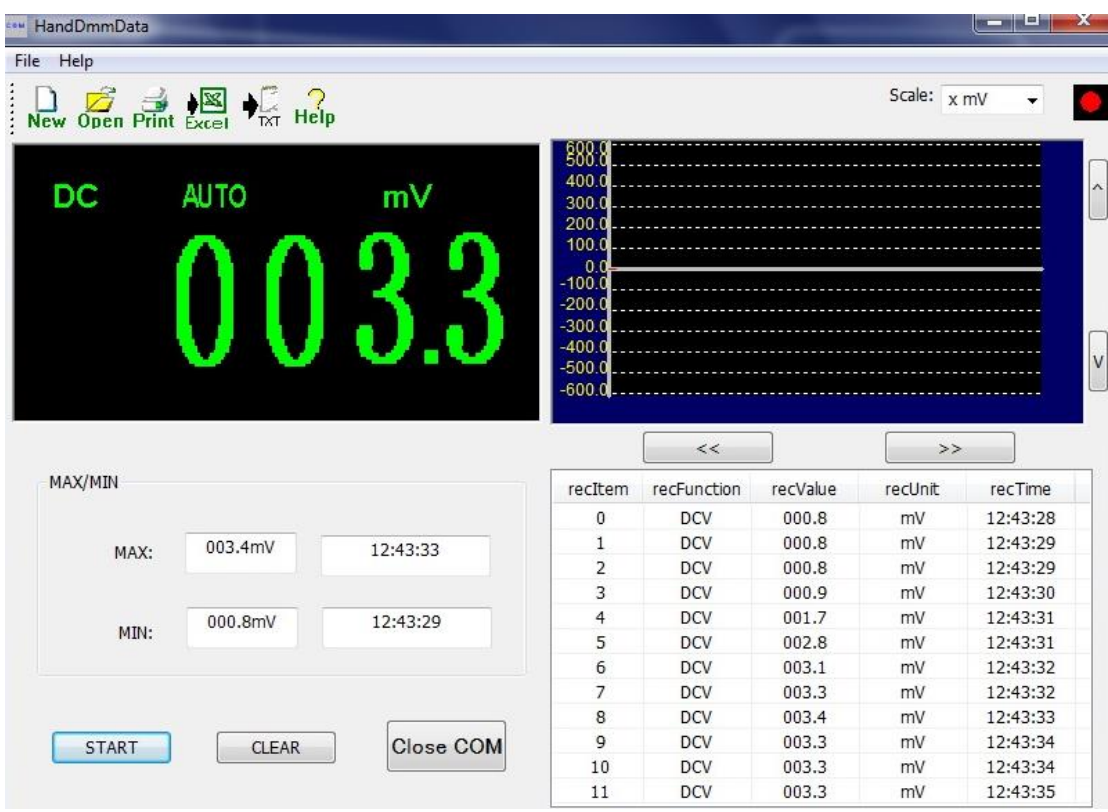

Fig. 2. Data acquisition using the presented experimental stand. 
The experimental steps are:

- voltage measurement of the electrical current at cutting, for 18 cutting edges from each batch, with the installation presented in Figure 1;

- analysis of the voltage values of the resulted electrical current;

- drawing a set of conclusions about the quality of the cutting inserts batches.

The experiments were done on 1C45 material which has the following chemical composition: $\mathrm{C}=0.45 \%, \mathrm{Si}=0.22 \%, \mathrm{Mn}=0.56 \%, \mathrm{P}=0.025 \%, \mathrm{~S}=0.034$. The tensile strength of $1 \mathrm{C} 45$ steel is $660 \mathrm{MPa}\left(66 \mathrm{daN} / \mathrm{mm}^{2}\right)$ and the hardness is $224 \mathrm{HB}$.

The tests results for 18 cutting edges from each batch (producer $\mathrm{A}, \mathrm{B}$ and $\mathrm{C}$ ) are centralized in Table 1.

Table 1. Obtained values for cutting electrical current voltage at turning 1C45 steel with cutting inserts from producer $\mathrm{A}, \mathrm{B}$ and $\mathrm{C}$.

\begin{tabular}{|c|c|c|c|c|c|c|}
\hline $\begin{array}{c}\text { No. of } \\
\text { edge }\end{array}$ & $\begin{array}{l}\text { Cutting } \\
\text { depth } \\
\text { [mm] }\end{array}$ & $\begin{array}{l}\text { Cutting } \\
\text { speed } \\
\text { [m/min] }\end{array}$ & $\begin{array}{c}\text { Feed } \\
{[\mathrm{mm} / \mathrm{rev}]}\end{array}$ & $\begin{array}{c}\text { Voltage } \\
\text { "UA" }[\mathrm{mV}]\end{array}$ & $\begin{array}{c}\text { Voltage } \\
\text { “UB" }[\mathrm{mV}]\end{array}$ & $\begin{array}{c}\text { Voltage } \\
\text { "Uc" }[\mathrm{mV}]\end{array}$ \\
\hline 1 & \multirow{18}{*}{1.5} & \multirow{18}{*}{107} & \multirow{18}{*}{0.208} & 3.9 & 3.2 & 12.6 \\
\hline 2 & & & & 4.8 & 3.5 & 10.3 \\
\hline 3 & & & & 4.3 & 3.1 & 9.7 \\
\hline 4 & & & & 4.1 & 3.1 & 11.7 \\
\hline 5 & & & & 4.3 & 3.1 & 11.6 \\
\hline 6 & & & & 5 & 3.6 & 11 \\
\hline 7 & & & & 4.1 & 3.2 & 10.1 \\
\hline 8 & & & & 4.2 & 3.3 & 12.3 \\
\hline 9 & & & & 4 & 3.2 & 11.1 \\
\hline 10 & & & & 4.2 & 3.2 & 12 \\
\hline 11 & & & & 4.2 & 3.3 & 12.9 \\
\hline 12 & & & & 4.7 & 3.6 & 12.3 \\
\hline 13 & & & & 4.2 & 3.3 & 7.5 \\
\hline 14 & & & & 4.6 & 3.2 & 11.4 \\
\hline 15 & & & & 5.6 & 3.3 & 12.1 \\
\hline 16 & & & & 4.5 & 3.2 & 10.1 \\
\hline 17 & & & & 6.1 & 3.1 & 12.6 \\
\hline 18 & & & & 4.9 & 3.3 & 8.7 \\
\hline
\end{tabular}

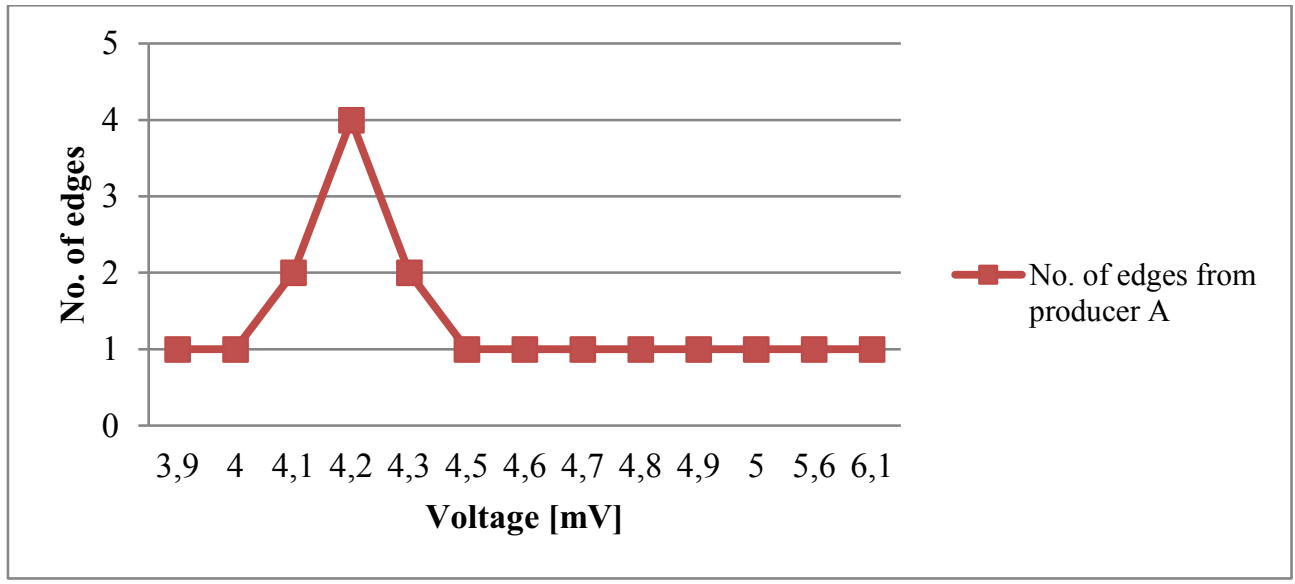

Fig. 3. Number of cutting edges from producer A that have the same value of the electrical current at cutting. 


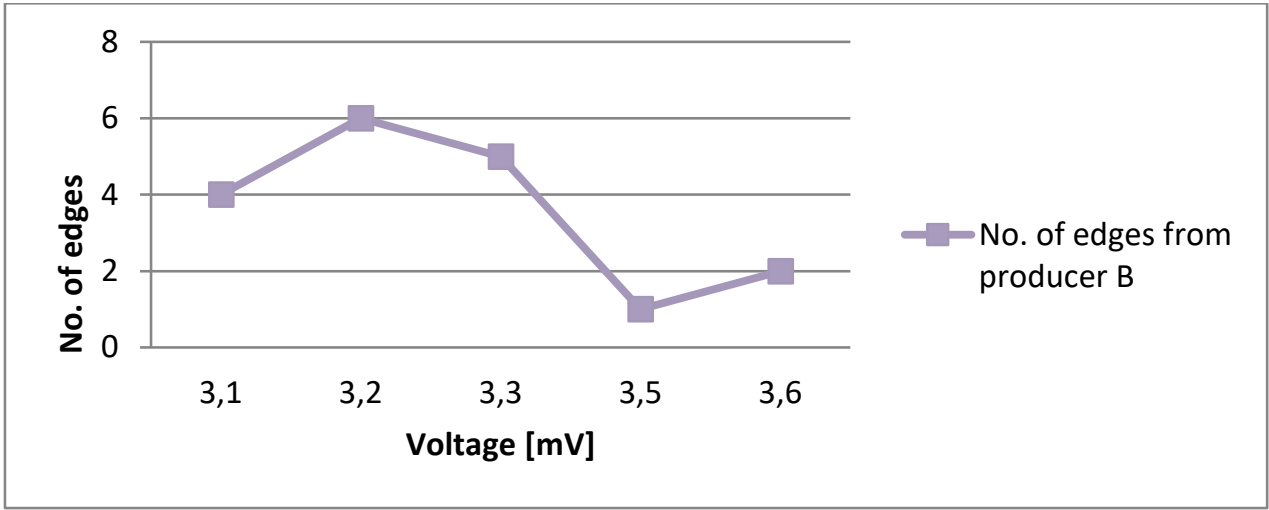

Fig. 4. Number of cutting edges from producer B that have the same value of the electrical current at cutting.

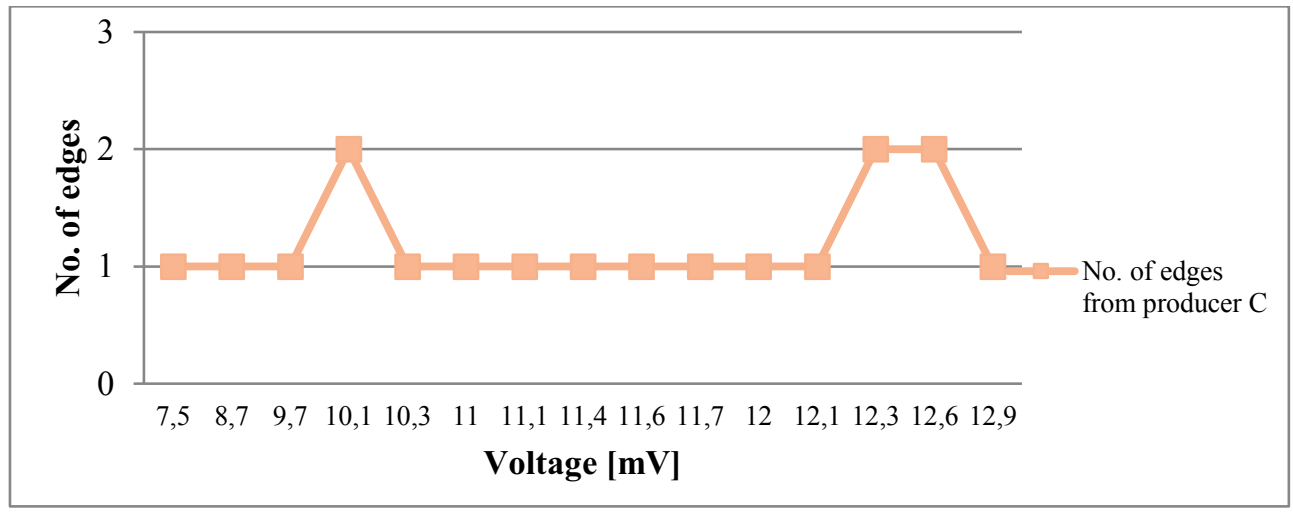

Fig. 5. Number of cutting edges from producer $C$ that have the same value of the electrical current at cutting.

The graphical representations from Figures 3, 4 and 5 are based on the data from Table 1 , and present, for each producer, the number of cutting edges that had the same voltage value of the electrical current at cutting.

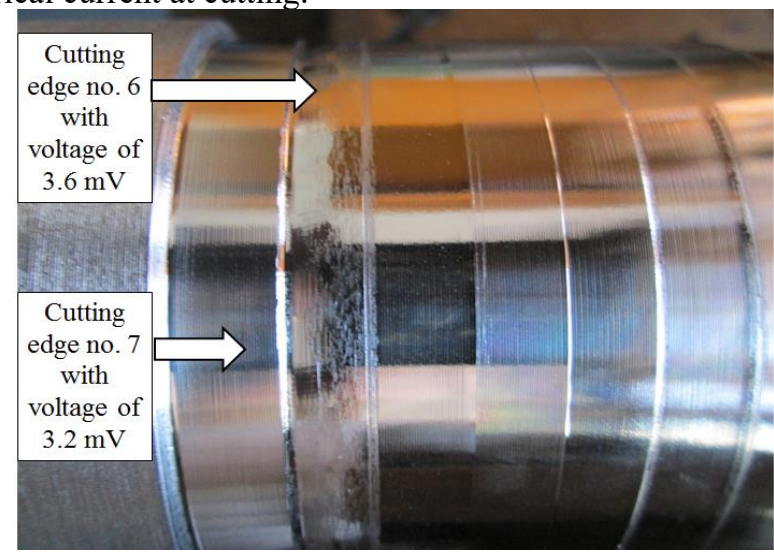

Fig. 6. Surface roughness obtained with cutting edges that had different voltages of the electrical current. 
During the experimental tries it was observed that the surface roughness is different when the value of the electrical current is different (Figure 6). For a higher value of the voltage, the surface roughness is greater.

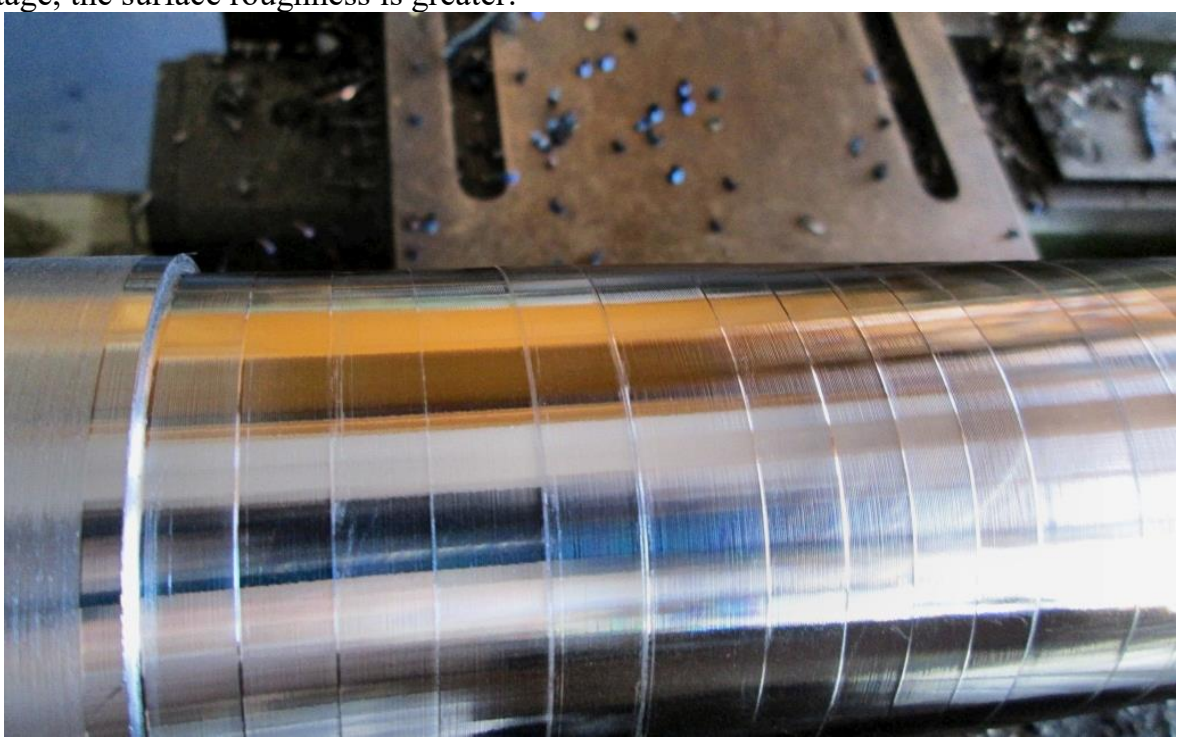

Fig. 7. Surface roughness obtained with cutting edges from producer $\mathrm{C}$.

It was also observed that even though the voltage of the electrical current for the edges from the producer $\mathrm{C}$ is higher, the surface quality is good (Figure 7), fact that leads to the conclusion that the titan coating of the plate is improperly done, the titan layer being very thin and it is easily exfoliated.

During the experimental tries it was also observed that the shape of the rake surface for producer A, presented in Figure 8, leads to chip fragmentation only when the cutting depth is greater than the nose radius of the cutting insert.

Producer A

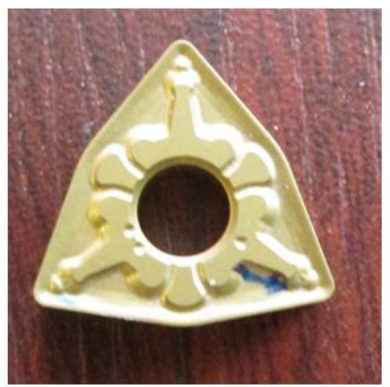

Producer B

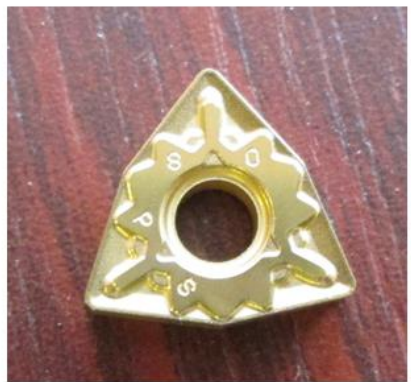

Producer C

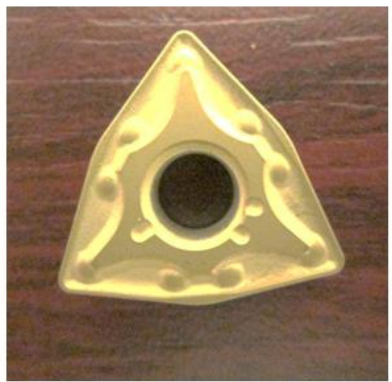

Fig. 8. Rake surfaces for cutting inserts from producers A, B and C.

Analysing the data from Table 1 and the graphics from Figures 3, 4 and 5 it can be observed that the qualitative order of the producers is: the cutting inserts from producer $\mathrm{B}$ present the best quality, followed by cutting inserts from producer $\mathrm{A}$, and producer $\mathrm{C}$ presents the lowest quality. 


\section{Economical analysis of three metallic carbide batches from 3 different producers}

The metallic carbide cutting inserts coated with titanium were acquisitioned with the next prices: inserts from producer A with 8.2 EUR, from producer B with $10 \mathrm{EUR}$, and from producer $\mathrm{C}$ with 8.5 euro.

It was calculated the average value of the voltage of electrical current at cutting obtained for the analysed edges from each batch and the results are: for producer $\mathrm{A}$ the average voltage is $4.54 \mathrm{mV}$, for producer $\mathrm{B}$ is $3.24 \mathrm{mV}$ and for producer $\mathrm{C}$ is $11.11 \mathrm{mV}$.

Considering the producer $\mathrm{B}$ as reference, the tool life for cutting inserts from producer A is with $40 \%$ lower, and for the cutting inserts from producer $\mathrm{C}$ is with $242 \%$ lower. The tool life proportions were calculated inversely proportional with the differences between the average voltage values obtained for the cutting inserts from the three producers.

The cost difference at the acquisition of a cutting insert from producer B and from producer $\mathrm{A}$, taking producer $\mathrm{B}$ as reference, is $18 \%$, and the cost difference at the acquisition of a cutting insert from producer $\mathrm{C}$ is $15 \%$. Considering the tool life differences, results that for an acquisitioned cutting insert from producer $\mathrm{B}$, rather than from producer $\mathrm{A}$, it is made an economy of 2,2 EUR/ insert. The comparison with cutting inserts from producer $\mathrm{C}$ cannot be made because these are improperly coated with titanium.

\section{Conclusions}

Due to the experiments, the next conclusions are drawn:

- the voltage of electrical current at cutting can easily determinate the tool life differences between the same type of cutting inserts;

- in this research it was observed that the cutting inserts from producer B lead to a greater economy if we consider also their tool life;

- it was observed a connection between surface roughness and electrical current at cutting when turning with cutting edges from the same producer;

- the experimental tries conducted to the conclusion that the titanium coating for the cutting inserts from producer $\mathrm{C}$ was improperly done.

\section{References}

1. R. Daicu, G. Oancea, AMM 808, 40 (2015)

2. H. Bagchi, S.K. Basu, Wear 26, 39 (1973)

3. A.L. Plotnikov, E.G. Krylov, E.M. Frolov STIN 1, 2 (2009)

4. M. Murata, S. Kurokawa, O. Ohnishi, CSME 79, 2546 (2013)

5. M. Murata, S. Kurokawa, O. Ohnishi, M. Uneda, T. Doi, CSME 6, 958 (2012)

6. H. Hirota, M. Murata, A. Kojima, K. Yanagihara, JSPE 64, 1191 (1998)

7. V. Diţu, AJME 8, 18 (2010)

8. R. Tanaka, A. Hosokawa, K. Yamada, T. Ueda, Proceedings of the Seventh International Conference on Progress of Machining Technology, 786 (2004)

9. V. Diţu, G. Oancea, R. Daicu, MATEC Web Conf. 94, 02005 (2017)

10. R. Daicu, V. Diţu, G. Oancea, MATEC Web Conf. 112, 01023 (2017)

11. A.K.M. Nurul Amin, M. R. A. Sarker, M. Ahmed, A.N. M. Karim, J. Mater. Process. Technol 77, (1998)

12. V. Diţu, B. Lepădătescu, WSEAS 12, (2013) 